\title{
Very Fast and Accurate Procedure for the Characterization of Photovoltaic Panels from Datasheet Information
}

\author{
Antonino Laudani, ${ }^{1}$ Francesco Riganti Fulginei, ${ }^{1}$ Alessandro Salvini, ${ }^{1}$ \\ Gabriele Maria Lozito, ${ }^{1}$ and Salvatore Coco ${ }^{2}$ \\ ${ }^{1}$ Department of Engineering, Università di Roma Tre, Via Vito Volterra 62, 00146 Roma, Italy \\ ${ }^{2}$ DIEEI, Università di Catania, Viale A. Doria 6, 95125 Catania, Italy
}

Correspondence should be addressed to Francesco Riganti Fulginei; riganti@uniroma3.it

Received 1 November 2013; Accepted 12 February 2014; Published 24 March 2014

Academic Editor: Ismail H. Altas

Copyright (C) 2014 Antonino Laudani et al. This is an open access article distributed under the Creative Commons Attribution License, which permits unrestricted use, distribution, and reproduction in any medium, provided the original work is properly cited.

\begin{abstract}
In recent years several numerical methods have been proposed to identify the five-parameter model of photovoltaic panels from manufacturer datasheets also by introducing simplification or approximation techniques. In this paper we present a fast and accurate procedure for obtaining the parameters of the five-parameter model by starting from its reduced form. The procedure allows characterizing, in few seconds, thousands of photovoltaic panels present on the standard databases. It introduces and takes advantage of further important mathematical considerations without any model simplifications or data approximations. In particular the five parameters are divided in two groups, independent and dependent parameters, in order to reduce the dimensions of the search space. The partitioning of the parameters provides a strong advantage in terms of convergence, computational costs, and execution time of the present approach. Validations on thousands of photovoltaic panels are presented that show how it is possible to make easy and efficient the extraction process of the five parameters, without taking care of choosing a specific solver algorithm but simply by using any deterministic optimization/minimization technique.
\end{abstract}

\section{Introduction}

The one-diode model for the photovoltaic (PV) panel characterization has been widely used within both specific software toolboxes for the estimation and the prediction of the electrical power produced by PV plants [1-4] and algorithms for the Maximum Power Point Tracking [5-7] or irradiance measurements $[8,9]$. Indeed, it guarantees a good tradeoff between accuracy and complexity for its setup [10, 11]. On the other hand, the extraction of the five-parameter model at standard reference conditions (SRC) (i.e., an inverse problem) has been widely faced in the literature. Although two approaches are generally the most adopted (the one that uses the datasheet information and the other one that exploits the experimental data on $I-V$ curves), the use of only data provided by manufacturer on datasheet appears more interesting because it does not require a specific experimental study on PV module. Nevertheless, the approaches proposed the in literature differ between them and often it is difficult to understand what is the best one to be used. Indeed, on one hand several works proposed different equations/approaches for the extraction of the five parameters; on the other hand, almost any kinds of optimization techniques have been presented to solve the inverse problem of the extraction of the five parameters. This is essentially due to the nature of the involved equations which are transcendental and hard to manage. Just to give some references within the wide literature regarding this issue, hereafter some of the more recent works are briefly reported. Regarding the techniques for finding the inverse problem solutions, in [12] an improved differential evolution algorithm is presented for the extraction of five parameters from both synthetic data and experimental $I V$ data, in [13] penalty differential evolution is used in a similar way, in $[14,15]$ pattern search and Bacterial Foraging Algorithm are used, respectively, and so on (see the reference within these works for further journal articles). Regarding the alternative analytical approaches, in [16] an explicit $I-V$ model of a solar cell which uses Padé 


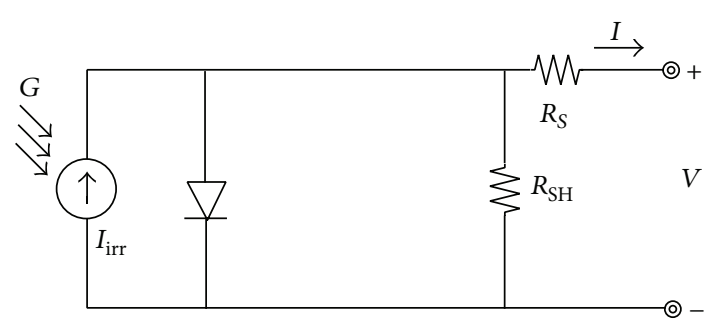

Figure 1: One-diode equivalent model for a PV module.

approximation is presented, that is, the exponential function is approximated by means of a rational function; in [17] the Taylor series is instead used; in [18-20] the $I-V$ relations are more explicitly written by means of the $W$ Lambert function [21], and then the extraction of the five parameters is performed by numerical techniques. Although the aim of these works is to effectively solve the problem, they suffer from unsuitable mathematical approximations (which lead to errors in the results) or complicated implementations and high computational costs. As a consequence these approaches are not so easy to be applied.

In this paper we present a fast and accurate procedure for obtaining the parameters of the five-parameter model by starting from its reduced form [22] which allows the identification of thousands of PV panels available on the standard databases (such as Californian Energy Commission database [23]). Indeed, by using suitable initial guesses it is possible to fully characterize thousands of PV panel in few seconds without any model simplifications or data approximations, simply by introducing further important mathematical considerations about the five-parameter model. The paper is structured as follows: in Section 2 the traditional onediode model and the problem related to its characterization are presented; in Section 3 the reduced form of the fiveparameter model is described; the validation results obtained on thousands of PV panels are shown in Section 4; finally, Section 5 is for the conclusions.

\section{The One-Diode Model and Its Reduced Form}

The equivalent circuit of the one-diode model is shown in Figure 1. The relation between current $I$ and voltage $V$ for a PV array/panel of arbitrary dimension $\left(N_{P}\right.$ parallel connected strings of $N_{S}$ series-connected PV cells) at the equivalent port is [10]

$$
\begin{aligned}
I= & N_{P} I_{\mathrm{irr}}-N_{P} I_{0}\left[e^{q\left(V+I\left(N_{S} / N_{P}\right) R_{S}\right) / N_{S} n k T}-1\right] \\
& -\frac{V+I\left(N_{S} / N_{P}\right) R_{S}}{\left(N_{S} / N_{P}\right) R_{\mathrm{SH}}},
\end{aligned}
$$

where $I_{\text {irr }}$ is the irradiance current (photocurrent), $I_{0}$ is the cell reverse saturation current (diode saturation current), $q$ is the electron charge $\left(q=1.602 \times 10^{-19} \mathrm{C}\right), n$ is the cell ideality factor, $k$ is the Boltzmann constant $(k=1.3806503 \times$ $\left.10^{-23} \mathrm{~J} / \mathrm{K}\right), T$ is the cell temperature, and $R_{S}$ and $R_{\mathrm{SH}}$ represent the cell series and shunt resistance, respectively. In (1), the governing variables $n, R_{S}, I_{\mathrm{irr}}, I_{0}$, and $R_{\mathrm{SH}}$ can be assumed as dependent or not on the irradiance $(G)$ and the temperature $(T)$ but in any case they are in function of certain reference (ref) parameters at SRC $\left(G_{\text {ref }}=1000 \mathrm{~W} / \mathrm{m}^{2}, T_{\text {ref }}=25^{\circ} \mathrm{C}\right)$ (hereafter we present and utilize the relations proposed by De Soto et al. in [11]; other slightly different relations are presented in several works, such as $[24,25]$, but their use does not affect the effectiveness and validity of the presented procedure):

$$
\begin{gathered}
n=n_{\text {ref }}, \\
R_{S}=R_{S, \text { ref }}, \\
I_{\text {irr }}=\frac{G}{G_{\text {ref }}}\left[I_{\text {irr,ref }}+\alpha_{T}\left(T-T_{\text {ref }}\right)\right], \\
I_{0}=I_{0, \text { ref }}\left[\frac{T}{T_{\text {ref }}}\right]^{3} e^{\left[E_{g, \text { ref }} / k T_{\text {ref }}-E_{g} / k T\right]} \\
R_{\mathrm{SH}}=\frac{G}{G_{\text {ref }}} R_{\mathrm{SH}, \text { ref }}
\end{gathered}
$$

In (5) $E_{g}=1.17-4.73 \times 10^{-4} \times\left(T^{2} /(T+636)\right)$ is the bandgap energy for silicon in $\mathrm{eV}$. Thus, there are five unknown parameters at SRC, $n_{\text {ref }}, R_{S \text {,ref }}, I_{\text {irr,ref }}, I_{0 \text {,ref }}$, and $R_{\mathrm{SH}, \mathrm{ref}}$ to be found within (2)-(6). Then, by starting from their values and by using the above relations, it is possible to write the $I-V$ curves for every temperature and irradiance values. In order to determine these five unknowns we need five independent equations based on datasheet information. Usually the PV panel manufacturers provide several information on datasheet at standard reference conditions (SRC), that is, for the irradiance $G_{\text {ref }}$ and the temperature $T_{\text {ref }}$ : the values of the short-circuit current $\left(I_{\mathrm{SC}, \text { ref }}\right)$ and the open-circuit voltage $\left(V_{\mathrm{OC}, \mathrm{ref}}\right)$, the current and voltage values at the maximum power point $\left(I_{\mathrm{mp} \text {,ref }}\right.$ and $\left.V_{\mathrm{mp} \text {,ref }}\right)$. In addition, the datasheets report the temperature coefficients (or percentage) of both the short-circuit current $\left(\alpha_{T}\right.$ or $\left.\alpha_{T}^{\%}\right)$ and the open-circuit voltage $\left(\beta_{T}\right.$ or $\left.\beta_{T}^{\%}\right)$. On the basis of the three characteristic points, open-circuit, short-circuit, and maximum power points at SRC, it is possible to write the first four equations of the five-parameter model $[10,11,15,22,26]$ : indeed the first equation arises by writing (1) for the open-circuit (OC) condition; the second equation arises by using (1) for the short-circuit (SC) condition; the third equation arises by exploiting the current and voltage values at the maximum power point (MPP) condition. The fourth equation is written by imposing the slope of the $P-V$ curve (power versus voltage) over the MPP equal to zero, $d(V \cdot I) / d V=0$, that can be also expressed in terms of $I_{\mathrm{mp}, \mathrm{ref}} / V_{\mathrm{mp}, \mathrm{ref}}$ ratio. The last fifth equation used to complete the five-parameter model is written by exploiting the temperature dependence of (1) at the open-circuit condition and irradiance $G=$ $G_{\text {ref }}$ by using the previously stated temperature coefficients $\left(\alpha_{T}\right.$ and $\left.\beta_{T}\right)$ [10-12]. Before showing the five equations, it is useful to briefly recall the constants specified in (7) adopted in order to simplify the writing of the mathematical expressions. Furthermore, the temperature-dependent factor 


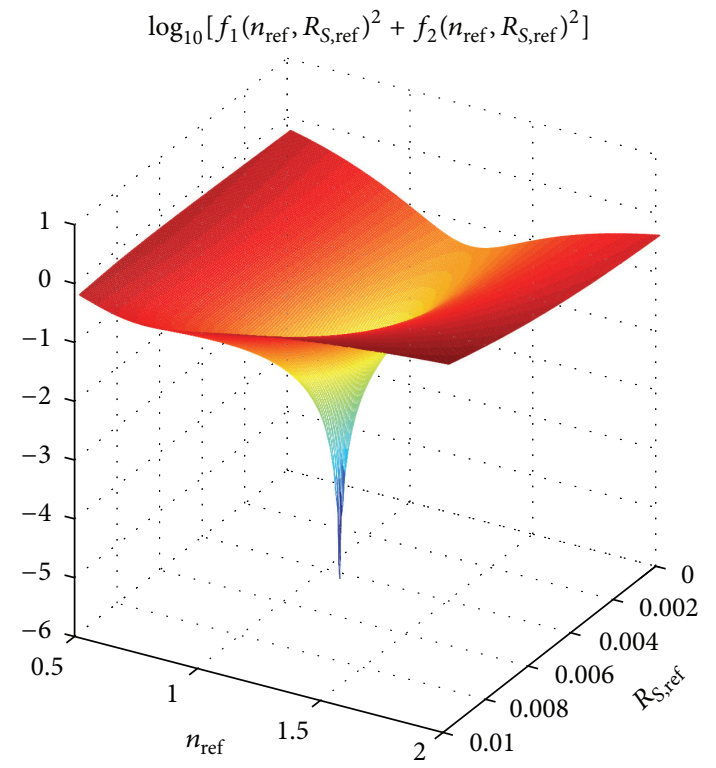

(a)

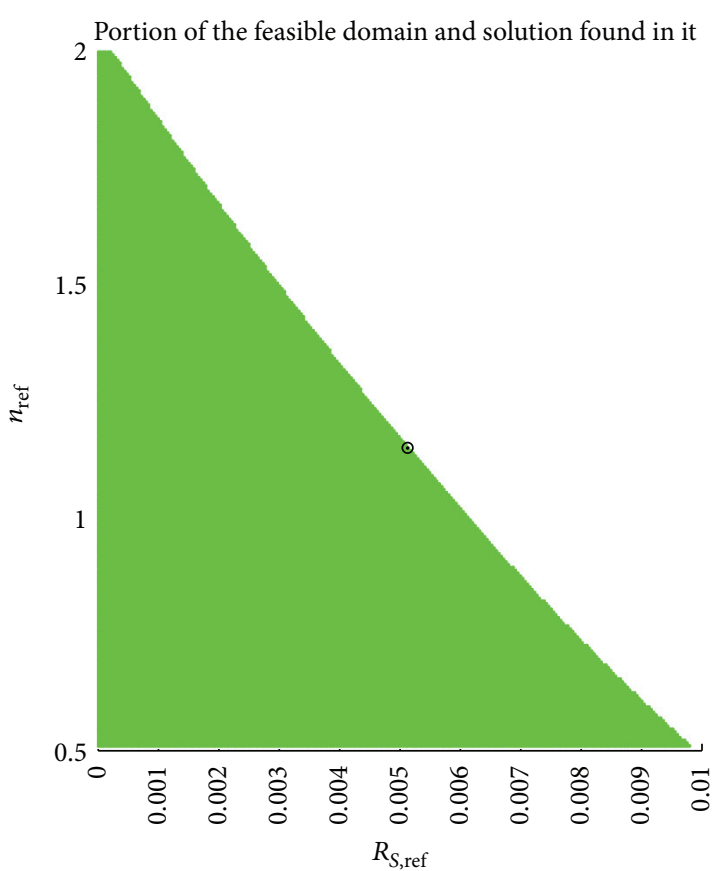

(b)

FIGURE 2: Graph of the functional (25) and the feasible domain for the BP 3235 T PV panel (multi-Si technology). A unique physical solution exists.

$K_{T}=\left[T / T_{\text {ref }}\right]^{3} e^{\left[E_{g, \text { ref }} / k T_{\text {ref }}-E_{g} / k T\right]}$ is used in (5) and the shunt conductance $G_{\mathrm{SH} \text {,ref }}=R_{\mathrm{SH} \text {,ref }}^{-1}$ is adopted as unknown in (6) instead of $R_{\mathrm{SH}, \mathrm{ref}}$ :

$$
\begin{gathered}
C_{1}=\frac{k T_{\mathrm{ref}}}{q} ; \quad C_{2}=\frac{V_{\mathrm{OC}, \mathrm{ref}}}{N_{S} C_{1}} ; \quad C_{3}=\frac{V_{\mathrm{mp}, \mathrm{ref}}}{N_{S} C_{1}} ; \\
C_{4}=\frac{I_{\mathrm{mp}, \mathrm{ref}}}{N_{P} C_{1}} ; \quad C_{5}=\frac{I_{\mathrm{SC}, \mathrm{ref}}}{N_{P} C_{1}} .
\end{gathered}
$$

Thus, the five equations are the following:

$$
\begin{aligned}
& 0=I_{\text {irr,ref }}-I_{0, \text { ref }}\left(e^{C_{2} / n_{\text {ref }}}-1\right)-G_{\mathrm{SH}, \mathrm{ref}} C_{1} C_{2}, \\
& C_{1} C_{5}=I_{\text {irr,ref }}-I_{0, \text { ref }}\left(e^{C_{5} R_{S, \text { ref }} / n_{\text {ref }}}-1\right)-C_{1} C_{5} G_{\text {SH,ref }} R_{S, \text { ref }} \text {, } \\
& C_{1} C_{4}=I_{\text {irr,ref }}-I_{0, \text { ref }}\left(e^{\left(C_{3}+C_{4} R_{S, \text { ref }}\right) / n_{\text {ref }}}-1\right) \\
& -G_{\mathrm{SH}, \mathrm{ref}} C_{1}\left(C_{3}+C_{4} R_{\mathrm{S}, \mathrm{ref}}\right) \\
& \frac{C_{4}}{C_{3}}=\frac{\left(I_{0, \text { ref }} / n_{\text {ref }} C_{1}\right) e^{\left(C_{3}+C_{4} R_{S, \text { ref }}\right) / n_{\text {ref }}}+G_{\mathrm{SH}, \text { ref }}}{1+\left(I_{0, \text { ref }} R_{S, \text { ref }} / n_{\text {ref }} C_{1}\right) e^{\left(C_{3}+C_{4} R_{\text {S,ref }}\right) / n_{\text {ref }}}+G_{\mathrm{SH}, \text { ref }} R_{S, \text { ref }}},
\end{aligned}
$$

$$
\begin{aligned}
0= & I_{\text {irr,ref }}+\alpha_{T}\left(T-T_{\text {ref }}\right) \\
& -I_{0, \text { ref }} K_{T}\left(e^{q\left(N_{S} C_{1} C_{2}+\beta_{T}\left(T-T_{\text {ref }}\right)\right) / N_{\mathrm{S}} n_{\text {ref }} k T}-1\right) \\
& -G_{\mathrm{SH}, \text { ref }} \frac{N_{S} C_{1} C_{2}+\beta_{T}\left(T-T_{\text {ref }}\right)}{N_{S}} .
\end{aligned}
$$

In (12), a value of $T=T_{\text {ref }} \pm 10 \mathrm{~K}$ is used, even if variations of temperature $\Delta T$ belonging to the range $[-10,+10]$ with respect to $T_{\text {ref }}$ return very similar solutions $[10,11]$.

The five-parameter model is thus defined by a system of five equations, (8)-(12), with the five unknowns (parameters), $n_{\text {ref }}, R_{S \text {,ref }}, I_{\text {irr,ref }}, I_{0, \text { ref }}$, and $G_{\mathrm{SH}, \text { ref }}$. Due to the presence of transcendental equations this problem is not so simple to manage and it can be only solved by means of numerical methods. Since it is practically an inverse problem, many minimization algorithms can be used and almost any kinds of computing techniques have been tested in the literature: for example, in [27] the comparison between several techniques to extract the five parameters is presented and compared by using the criteria of applicability, convergence, stability, calculation speed, and error on various types of $I V$ data. In addition, due to its nonlinear nature, the system returns solutions that are very sensitive to the choice of the initial guesses [22, 26, 27]. As the following section shows, this problem can be easily overwhelmed by using a reduced form of the model employing only a set of two equations in two unknowns. For the reader's convenience, the list of the technical parameters used in this work is reported at the end of the paper.

\section{Reduction to a Two-Parameter Model}

In [22] it has been proven that the five-parameter model can be reduced to a two-parameter model improving the efficiency of the algorithm finding the solution. By using this reduced form of the system instead of the original one, it is also possible to demonstrate: (i) the uniqueness of 


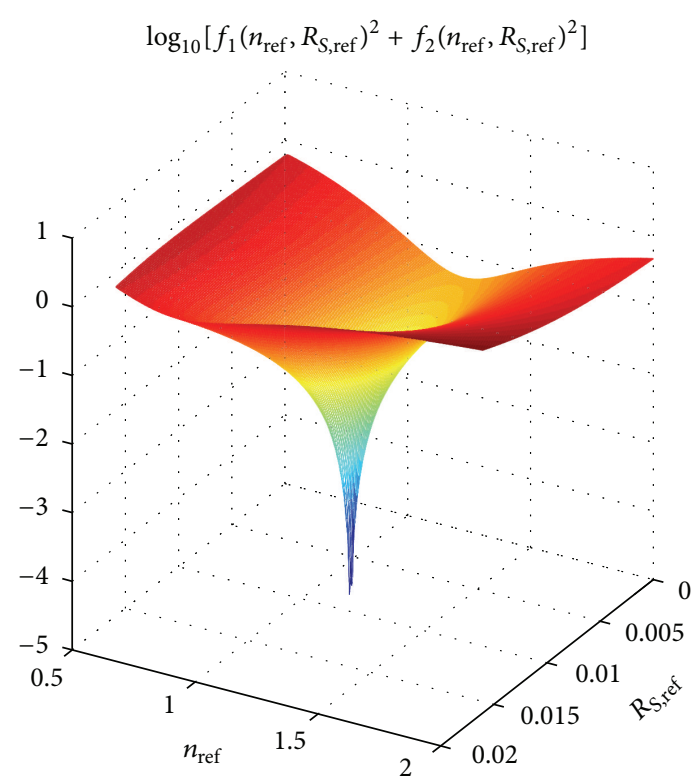

(a)

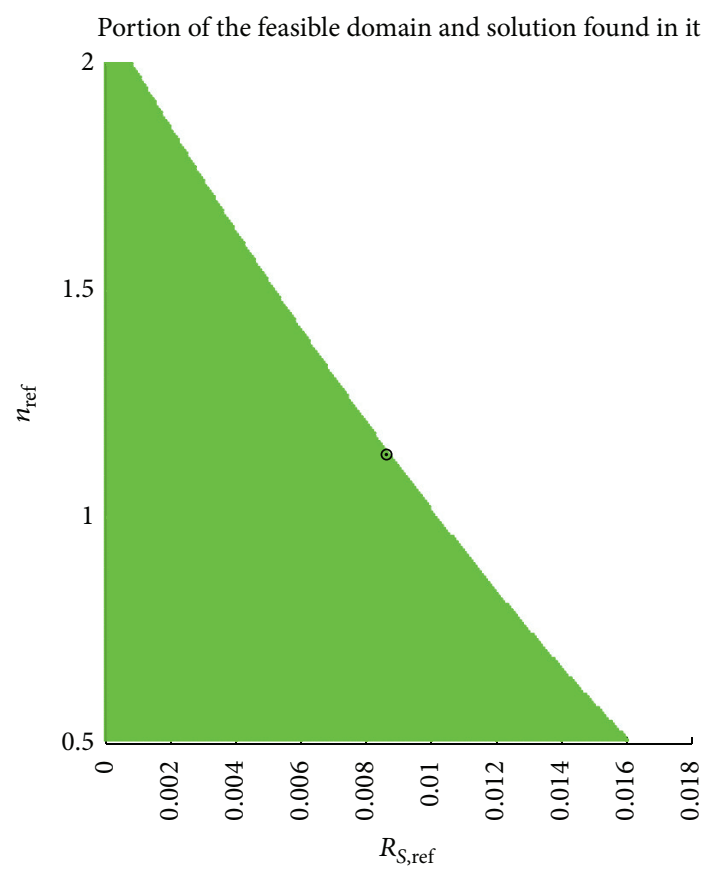

(b)

FIGURE 3: Graph of the functional (25) and feasible domain for the Sharp NT175 panel (mono-Si technology). A unique physical solution exists.

the solution for the problem; (ii) the existence of a unique solution without physical meaning for some PV panels; (iii) the matter of the optimal choice of the initial guesses that make easy and effective the solution of the inverse problem. As first thing, let us show the way to reduce the five-parameter model to a two-parameter model. This is obtained by simple algebraic manipulations of three of the five equations (8)-(11). Indeed from the first equation (8) it is possible to obtain $I_{\text {irr,ref }}$ as a function of $n_{\text {ref }}, R_{S \text {,ref }}$ and $R_{\mathrm{SH}, \text { ref }}$ as follows:

$$
I_{\text {irr,ref }}=I_{0}\left(e^{C_{2} / n_{\text {ref }}}-1\right)+G_{\mathrm{SH}, \text { ref }} C_{1} C_{2} .
$$

By substituting (13) in (10), it is possible to write

$$
\begin{aligned}
C_{1} C_{4}= & I_{0, \text { ref }}\left(e^{C_{2} / n_{\text {ref }}}-1\right)-I_{0, \text { ref }}\left(e^{\left(C_{3}+C_{4} R_{S, \text { ref }}\right) / n_{\text {ref }}}-1\right) \\
& -G_{S H, \text { ref }} C_{1}\left(C_{3}-C_{2}+C_{4} R_{S, \text { ref }}\right)
\end{aligned}
$$

that can be written also as

$$
I_{0, \text { ref }}=\frac{C_{1} C_{4}+G_{S H, \text { ref }} C_{1}\left(C_{3}-C_{2}+C_{4} R_{S, \text { ref }}\right)}{\left(e^{C_{2} / n_{\text {ref }}}-e^{\left(C_{3}+C_{4} R_{S, \text { ree }}\right) / n_{\text {ref }}}\right)} .
$$

On the other hand, from (11) we can also obtain $I_{0, \text { ref }}$

$$
I_{0, \text { ref }}=\frac{C_{3} G_{S H, \text { ref }}-C_{4}-C_{4} G_{S H, \text { ref }} R_{S, \text { ref }}}{e^{\left(C_{3}+C_{4} R_{S, \text { ref }}\right) / n_{\text {ref }}}\left(\left(C_{4} R_{S, \text { ref }}-C_{3}\right) / n_{\text {ref }} C_{1}\right)} .
$$

Furthermore, by posing the expression (15) equal to the (16), we can write

$$
\begin{aligned}
& \frac{C_{1} C_{4}+G_{\mathrm{SH}, \mathrm{ref}} C_{1}\left(C_{3}-C_{2}+C_{4} R_{S, \text { ref }}\right)}{\left(e^{C_{2} / n_{\text {ref }}}-e^{\left(C_{3}+C_{4} R_{\mathrm{S}, \mathrm{ref}}\right) / n_{\text {ref }}}\right)} \\
& =\frac{C_{3} G_{\mathrm{SH}, \mathrm{ref}}-C_{4}-C_{4} G_{\mathrm{SH}, \mathrm{ref}} R_{\mathrm{S}, \mathrm{ref}}}{e^{\left(C_{3}+C_{4} R_{S, \text { ref }}\right) / n_{\text {ref }}}\left(\left(C_{4} R_{S, \text { ref }}-C_{3}\right) / n_{\text {ref }} C_{1}\right)}
\end{aligned}
$$

from which it is possible to obtain $G_{\mathrm{SH}, \text { ref }}$ as a function of $n_{\text {ref }}$ and $R_{S \text {,ref }}$,

$$
\begin{aligned}
G_{\mathrm{SH}, \text { ref }} \\
=\frac{C_{4}}{C_{4} R_{S, \text { ref }}-C_{3}} \\
\quad \cdot \frac{\left(1+\left(C_{3}-C_{4} R_{S, \text { ref }}\right) / n_{\text {ref }}\right) e^{\left(C_{3}+C_{4} R_{S, \text { ref }}-C_{2}\right) / n_{\text {ref }}}-1}{1+\left(\left(C_{4} R_{S, \text { ref }}+C_{3}-C_{2}\right) / n_{\text {ref }}-1\right) e^{\left(C_{3}+C_{4} R_{S, \text { ref }}-C_{2}\right) / n_{\text {ref }}}} .
\end{aligned}
$$

Now, substituting (18) in (15) or (16) also allows expressing $I_{0, \text { ref }}$ as a function of $n_{\text {ref }}$ and $R_{S, \text { ref }}$,

$$
\begin{aligned}
& I_{0, \text { ref }} \\
& \quad=\frac{C_{1} C_{4}}{C_{3}-C_{4} R_{S, \text { ref }}} \\
& \quad \cdot \frac{\left(2 C_{3}-C_{2}\right)}{e^{C_{2} / n_{\text {ref }}}+\left(\left(C_{4} R_{S, \text { ref }}+C_{3}-C_{2}\right) / n_{\text {ref }}-1\right) e^{\left(C_{3}+C_{4} R_{S, \text { ref }}\right) / n_{\text {ref }}}} .
\end{aligned}
$$




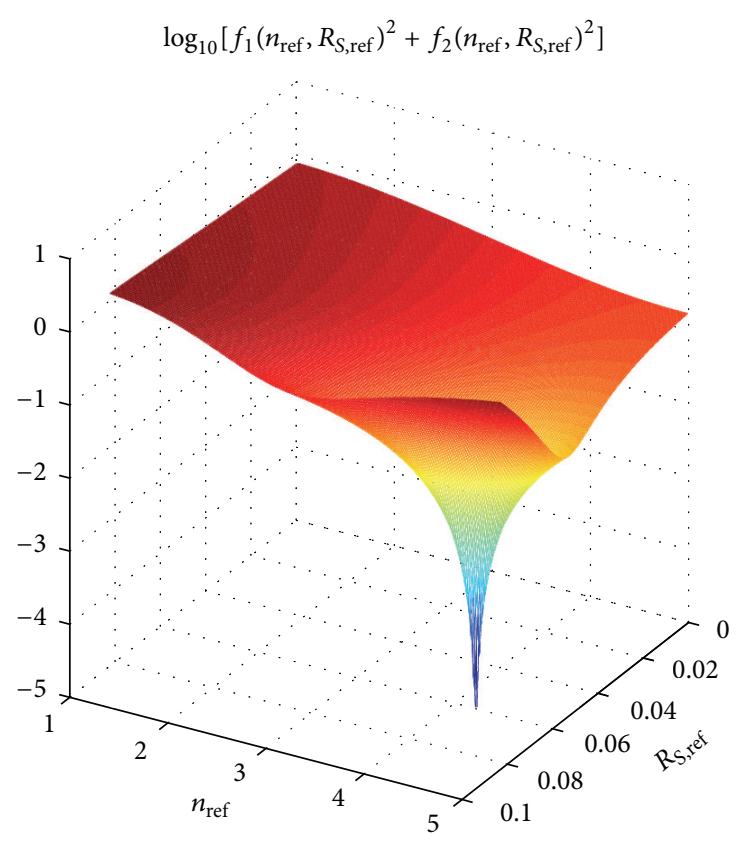

(a)

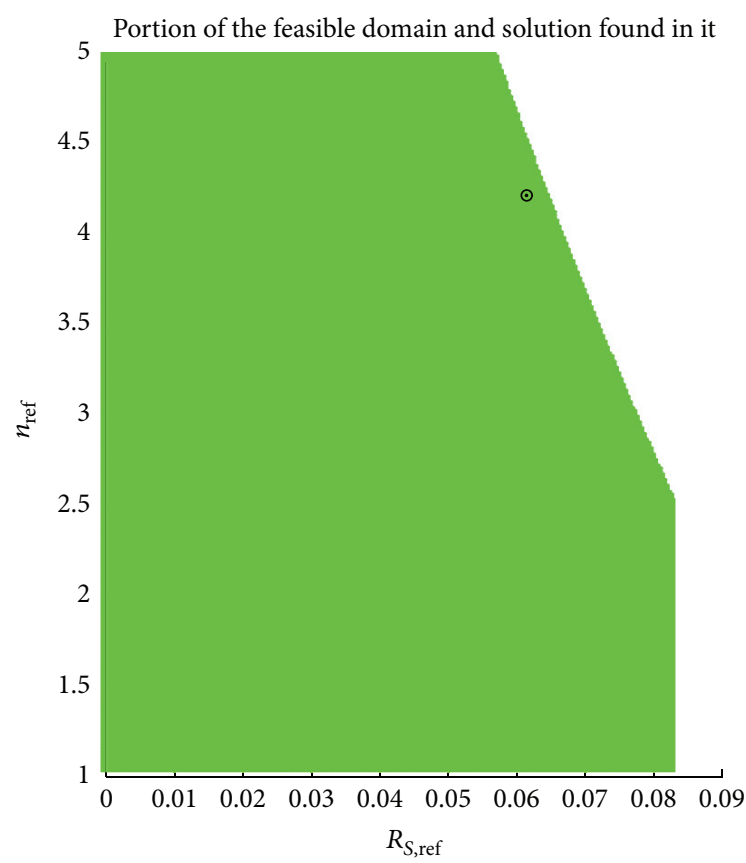

(b)

FIgURE 4: Graph of the functional (25) and feasible domain for the PV panel Xunlight XR12-88 panel (thin film technology). A unique physical solution exists.

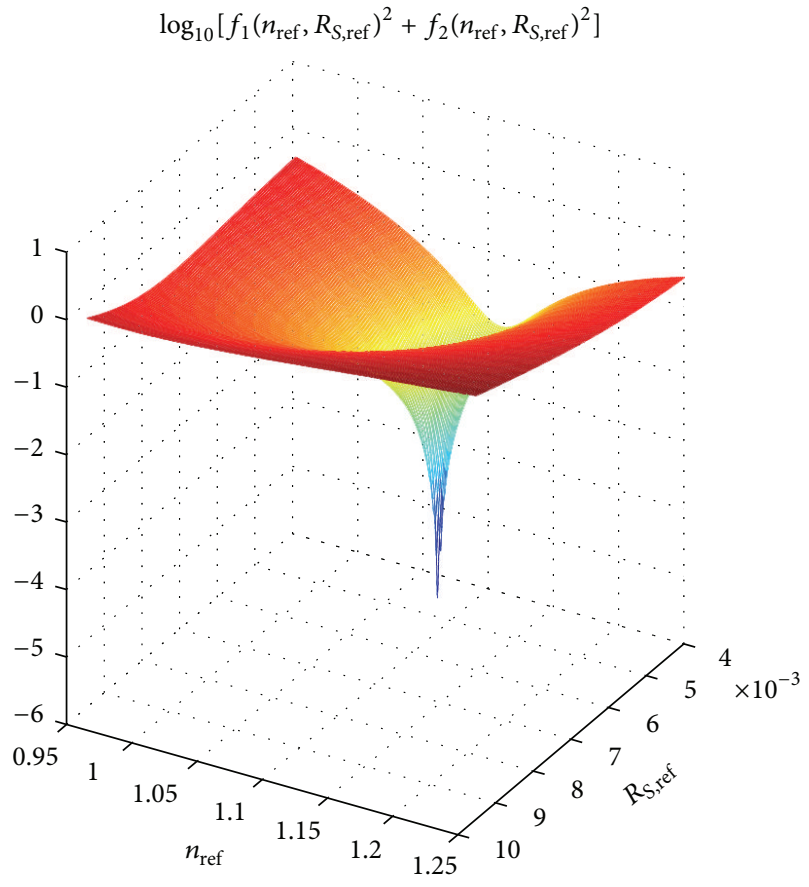

(a)

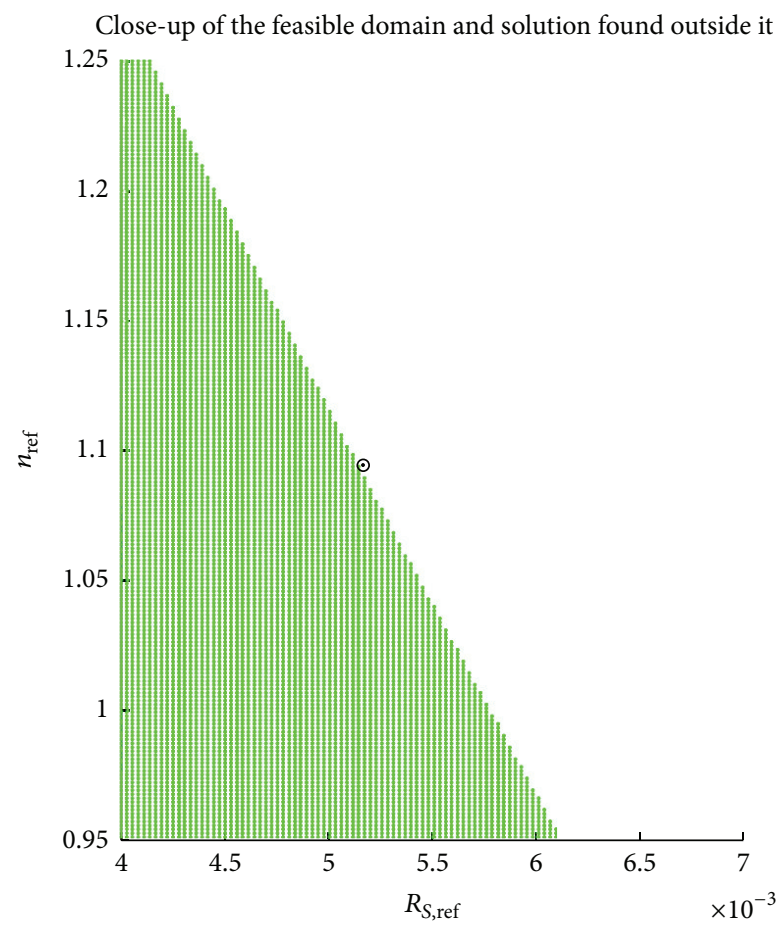

(b)

FIGURE 5: Graph of the functional (25) and feasible domain for the PV panel BP Q 230 panel (multi-Si technology). A unique unphysical solution exists (it lies outside the feasible domain); that is, this panel cannot be modelled by using the five-parameter model. 
Finally, (19) and (18) are utilized together with (13) so that $I_{\text {irr,ref }}$ can be written as a function of $n_{\text {ref }}$ and $R_{S \text {,ref }}$,

$$
I_{\text {irr,ref }}=\frac{C_{1} C_{4} C_{2}}{\left(C_{3}-C_{4} R_{S, \text { ref }}\right)}+\frac{\left(C_{1} C_{4}\left(2 C_{3}-C_{2}\right)\right) /\left(C_{3}-C_{4} R_{S, \text { ref }}\right)\left(e^{C_{2} / n_{\text {ref }}}-1-\left(C_{2} / n_{\text {ref }}\right) e^{\left(C_{3}+C_{4} R_{S, \text { ref }}\right) / n_{\text {ref }}}\right)}{e^{C_{2} / n_{\text {ref }}}+\left(\left(C_{4} R_{S, \text { ref }}+C_{3}-C_{2} / n_{\text {ref }}\right)-1\right) e^{\left(C_{3}+C_{4} R_{S, \text { ref }} / n_{\text {ref }}\right.}} .
$$

In (18), (19), and (20) we have written $G_{\mathrm{SH}, \text { ref }}, I_{0, \text { ref }}$, and $I_{\text {irr, ref }}$ as functions of $n_{\text {ref }}$ and $R_{S, \text { ref }}$, respectively. This means that now there are only two independent unknowns, called $n_{\text {ref }}$ and $R_{S, \text { ref }}$, to be found by using the two equations coming out from the other two conditions not yet utilized in the previous steps. They are (9) and (12) obtained from the evaluation of (1) at short-circuit $\left(V=0, I=I_{\mathrm{SC}, \text { ref }}\right)$ condition and for $\beta_{T} \approx\left(V_{\mathrm{OC}}-V_{\mathrm{OC}, \mathrm{ref}}\right) /\left(T-T_{\text {ref }}\right)$ condition, respectively. Thus, the reduced form of the original five-equation system is the following:

$$
\begin{aligned}
& \frac{C_{3}\left(2 C_{4}-C_{5}\right)}{C_{3}-R_{S, \text { ref }} C_{4}}+\frac{C_{4}\left(C_{2}-2 C_{3}\right)}{C_{3}-R_{S, \text { ref }} C_{4}} e^{\left(\left(C_{5} R_{S, \text { ref }}-C_{2}\right) / n_{\text {ref }}\right)} \\
& +\left[\frac{C_{5} C_{3}-C_{4} C_{2}}{C_{3}-R_{S, \text { ref }} C_{4}}-\frac{C_{2} C_{4}+C_{5} C_{3}-C_{5} C_{2}}{n_{\text {ref }}}\right] \\
& \times e^{\left(\left(C_{3}+R_{\text {S,ref }} C_{4}-C_{2}\right) / n_{\text {ref }}\right)}=0 \text {, } \\
& {\left[\alpha_{T}\left(T-T_{\text {ref }}\right)-\frac{\beta_{T}\left(T-T_{\text {ref }}\right) C_{4}}{N_{S}\left(C_{3}-R_{S, \text { ref }} C_{4}\right)}+\frac{C_{1} C_{4}\left(2 C_{3}-C_{2}\right)}{\left(C_{3}-R_{S, \text { ref }} C_{4}\right)}\right]} \\
& +\left[\alpha_{T}\left(T-T_{\text {ref }}\right)\left(\frac{C_{3}+R_{S, \text { ref }} C_{4}-C_{2}}{n_{\text {ref }}}-1\right)\right] \\
& \times e^{\left(\left(C_{3}+R_{S, r e f} C_{4}-C_{2}\right) / n_{\text {ref }}\right)} \\
& +\left[\frac{C_{4} \beta_{T}\left(T-T_{\text {ref }}\right)}{N_{S}} \frac{\left(n_{\text {ref }}-R_{S, \text { ref }} C_{4}+C_{3}\right)}{n_{\text {ref }}\left(C_{3}-R_{S, \text { ref }} C_{4}\right)}\right] \\
& \times e^{\left(\left(C_{3}+R_{\text {S,ref }} C_{4}-C_{2}\right) / n_{\text {ref }}\right)} \\
& +\frac{C_{1} C_{4} K_{T}\left(C_{2}-2 C_{3}\right)}{\left(C_{3}-R_{S, \text { ref }} C_{4}\right)} \\
& \times e^{\left(q \beta_{T}\left(T-T_{\text {ref }}\right) / N_{S} k T n_{\text {ref }}+\left(C_{2} / n_{\text {ref }}\right)\left(T_{\text {ref }} / T-1\right)\right)} \\
& +\frac{C_{1} C_{4}\left(K_{T}-1\right)\left(2 C_{3}-C_{2}\right)}{\left(C_{3}-R_{S, \text { ref }} C_{4}\right)} e^{\left(-C_{2} / n_{\text {ref }}\right)}=0 .
\end{aligned}
$$

3.1. Solution of the Reduced form of the Five-Parameter Model. Although the two equations (21) of the reduced form of the five-parameter model are transcendental equations, they are quite affordable that simple and fast numerical methods can be utilized to find the solutions instead of more complex and expensive algorithms in terms of computational costs [2831]. On the other hand, the effectiveness of the reduced form with respect to the original system based on five equations is evident since it returns the same unique solution also by using different numerical methods. Moreover, (18)-(21) allows making several important considerations about the solutions of the five-parameter model.

(i) Since the values of $I_{\text {irr,ref }}, I_{0, \text { ref }}$, and $R_{\mathrm{SH}, \text { ref }}$ must be positive in order to obtain a physical meaning for these three parameters, it is possible to find the conditions for the range of the independent unknowns $n_{\text {ref }}$ and $R_{S, \text { ref }}$ from (18), (19), and (20). In particular, the maximum admissible value for $R_{S \text {,ref }}$ is a function of $n_{\text {ref }}$, according to the following relations [22]:

$$
\begin{gathered}
R_{S, \text { ref }} \neq \frac{\left(C_{2}-C_{3}\right)}{C_{4}}, \\
0<R_{S, \text { ref }}<R_{S, \text { ref }}^{\max }\left(n_{\text {ref }}\right)
\end{gathered}
$$

with $R_{S, \text { ref }}^{\max }$ as a function of $n_{\text {ref }}$

$$
R_{S, \text { ref }}^{\max }\left(n_{\text {ref }}\right)=\frac{n_{\text {ref }}}{C_{4}}\left[1+W_{-1}\left(-e^{\left(C_{2}-n_{\text {ref }}-2 C_{3}\right) / n_{\text {ref }}}\right)\right]+\frac{C_{3}}{C_{4}}
$$

whereas the Lambert $W$ function [8] in (23) has been used: this special mathematical function allows obtaining a closed form representation for the $I-V$ curves and it is often successfully used for the analysis of PV modules [14, 15].

(ii) Thus it is possible to individuate the feasible domain for the two remaining independent unknowns by assuming

$$
0.5 \leqslant n_{\text {ref }} \leqslant 2.5
$$

(iii) It is also possible to graph the 2D functional used for solving the system (21):

$$
F\left(n_{\text {ref }}, R_{S, \text { ref }}\right)=f_{1}\left(n_{\text {ref }}, R_{S, \text { ref }}\right)^{2}+f_{2}\left(n_{\text {ref }}, R_{S, \text { ref }}\right)^{2},
$$

where $f_{1}\left(n_{\text {ref }}, R_{S, \text { ref }}\right)=0$ and $f_{2}\left(n_{\text {ref }}, R_{S, \text { ref }}\right)=0$ represent the first and the second equation of the system (21), respectively. The graph of the functional $F\left(n_{\text {ref }}, R_{S, \text { ref }}\right)$ is smooth and free from local minima (some examples are shown in the next section). The presence of only one minimum (i.e., one global minimum) makes the problem of finding the solution of the system (21) a convex problem allowing the use of simple initial guesses without choosing specific optimization algorithms. Indeed, as also discussed in [26] where an empirical approach is adopted, 


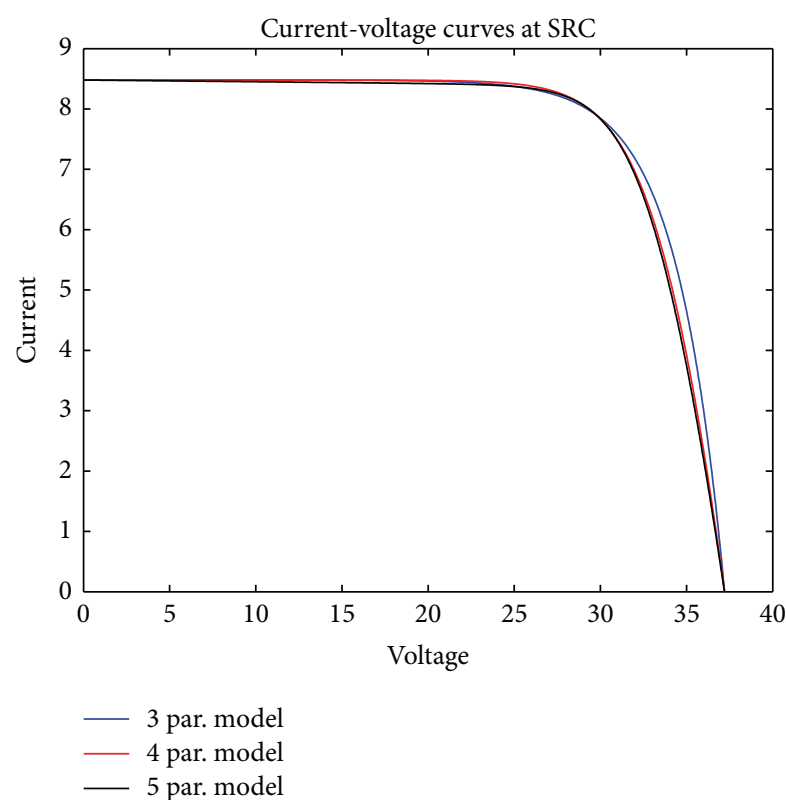

FIgURE 6: Current-Voltage curves at SRC of BP 3 235T, traced by using $3 / 4 / 5$ parameter models.

the choice of the initial guesses is one of the more critical aspects regarding the identification of the fiveparameter model [22].

(iv) As a consequence, it is also possible to state that the system (21), that is, the reduced form of the original five-equation system, has a unique solution that corresponds to the one with physical meaning.

(v) By observing the graph of the functional $F\left(n_{\text {ref }}, R_{\mathrm{S}, \text { ref }}\right)$ it is also possible to verify that some PV panels have the minimum (i.e., the solution of the problem) lying outside the feasible domain. This means that the solution still exists but it is not physical (i.e., at least one among the five parameters is negative).

3.2. Some Examples and Graphs. In order to prove the above considerations, in Figures 2, 3, 4, and 5 the results of four different panel modules are shown: a mono-Si PV panel (Sharp NT-175UC1), a multi-Si PV panel (BP 3235 T), a thin film PV panel (Xunlight XR12-88), and another multi-Si PV panel (BP Q Series $230 \mathrm{~W}$ ). Each figure shows the graph of the functional $F\left(n_{\mathrm{ref}}, R_{\mathrm{S}, \mathrm{ref}}\right)$ together with its feasible domain (i.e., the set of points of the two independent parameters $n_{\text {ref }}$ and $R_{S, \text { ref }}$ for which the dependent parameters $I_{0, \text { ref }}, I_{\text {irr,ref }}$ and $G_{\mathrm{SH}, \mathrm{ref}}$, have physical meaning) and the solution (minimum of the functional) of the reduced system (21). Figures 25 clearly prove the uniqueness of the solutions of the four panels. Furthermore, the quasi-monotonic behaviours of the functionals allow for an easy search of the solution (convex optimization). The initial guesses chosen for the search procedure of the solutions were the following:

$$
R_{S}^{\text {guess }}=0.9 \cdot R_{S, \text { ref }}^{\max }\left(n^{\text {guess }}\right)
$$

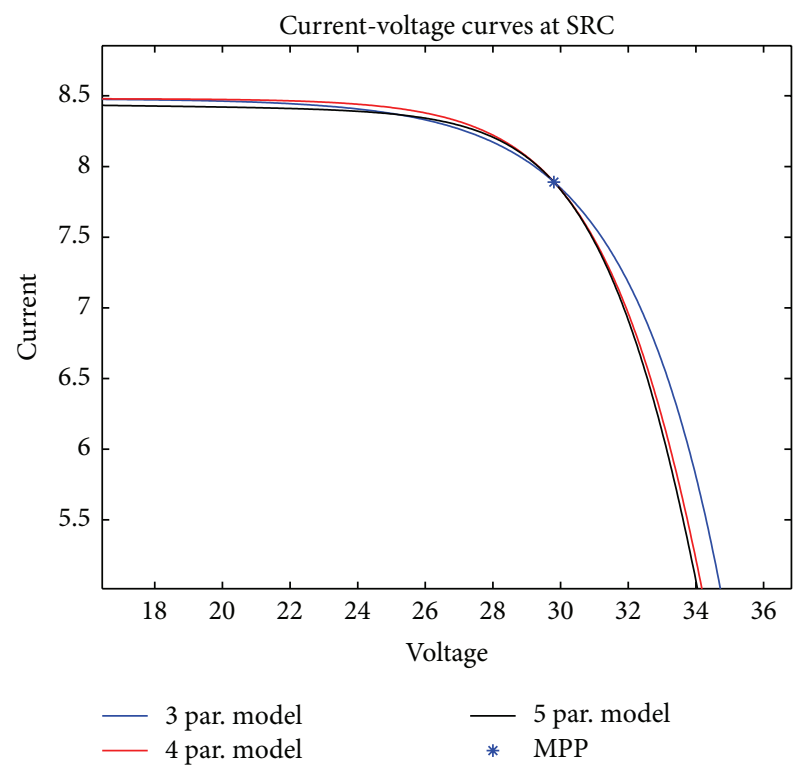

FIGURE 7: Close-up around maximum power point of CurrentVoltage curves at SRC of BP $3235 \mathrm{~T}$, traced by using 3/4/5 parameter models.

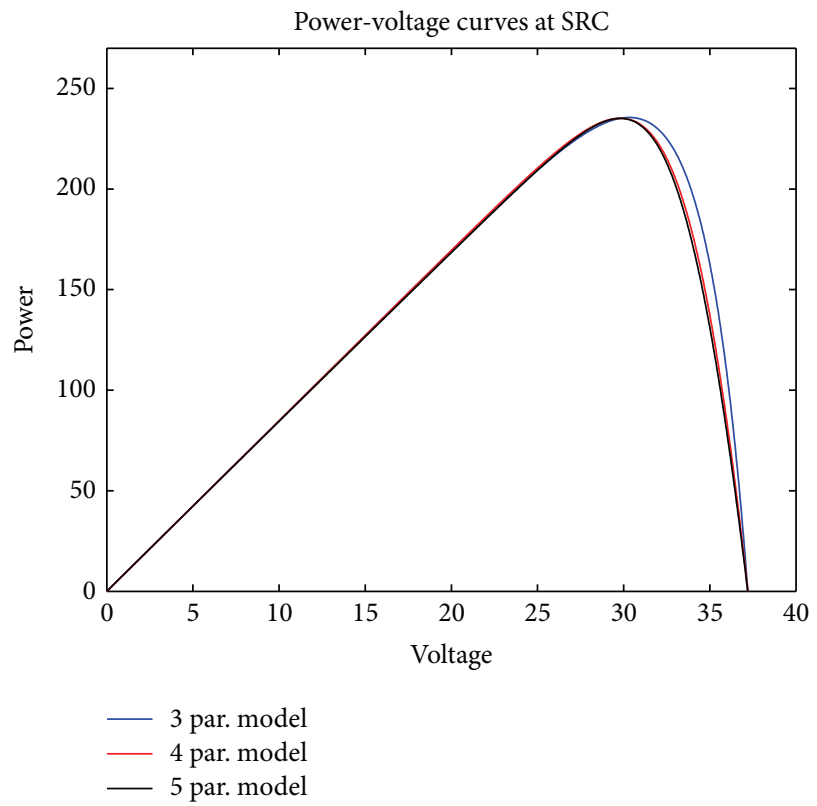

FIGURE 8: Power-Voltage curves at SRC of BP 3 235T, traced by using 3/4/5 parameter models.

with $n^{\text {guess }}=1.0$ for multi-Si and mono-Si PV panels and $n^{\text {guess }}=2.0$ for thin film PV panels. It can be noted by observing Figure 5 that the PV panel BP Q Series $230 \mathrm{~W}$ does not provide for physical solutions of the five parameters model (i.e., the solution exists but it lies outside the feasible domain and then at least one among the dependent parameters is lower than zero). It is worth noting that all the PV panels of BP Q series cannot be modelled by using the five-parameter model. The issue about the existence or not of the solution 


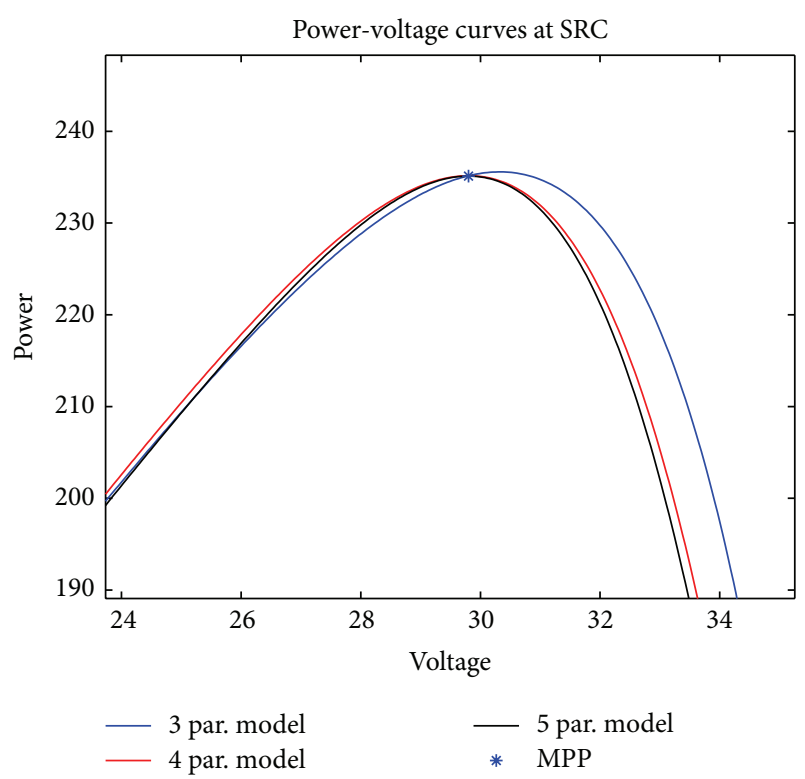

FIgURE 9: Close-up around maximum power point of Power-Voltage curves at SRC of BP 3 235T, traced by using 3/4/5 parameter models.

is really complex and nothing can be said a priori by simply observing the datasheets of the PV panels.

\section{Tests on California Energy Commission Database}

In order to prove the effectiveness of the proposed procedure, aimed at the identification of the five-parameter model simply by starting from PV datasheets, in this section a statistical validation is presented. In particular, the tests have involved around 11000 PV panels belonging to the California Energy Commission (CEC) database [23] (updated monthly). Table 1 shows the number of tested PV panels (\# PV panels) from CEC database grouped by type of technology. With the aim to demonstrate both the robustness and the fastness of the proposed approach, several initial guesses have been chosen and three different numerical algorithms/functions have been used in Matlab: $f$ solve (suitable for systems with nonlinear equations), fminsearch (generic unconstrained minimization function), and lsqnonlin (function aimed to solve least squares problems). The simulations showed very accurate results (i.e., with functional values less than $1 E-20$ ) which are independent of the adopted algorithm and the unique solutions have been found at first launch for almost all panels. The execution time for the extraction of the five parameters of all the $11764 \mathrm{PV}$ shown in Table 1 performed on an Intel i5 core $2.5 \mathrm{GHz}$ based notebook with $4 \mathrm{~GB}$ of RAM was around 90 seconds for the most efficient algorithm (fsolve with trust-region-dogleg) and 400 seconds for the slowest algorithm (fsolve with trust-region-reflective). This means that, also for the worst cases, the herein proposed extraction procedure of the five parameters spent less than $30 \mathrm{msec}$ for each panel.
TABLE 1: Number of tested PV panels from CEC database grouped by type of technology.

\begin{tabular}{lc}
\hline Technology & \# PV panels \\
\hline Mono-Si & 4801 \\
Multi-Si & 6435 \\
Amorphous and thin films & 253 \\
Other (CIS, CIGS, CdTe, etc.) & 275 \\
\hline Total & 11764 \\
\hline
\end{tabular}

TABLE 2: Results obtained with Matlab fsolve for $R_{S}^{\text {guess }}=$ $0.5 R_{S, \text { ref }}^{\max }\left(n^{\text {guess }}\right)$.

\begin{tabular}{lccc}
\hline Algorithm & $\begin{array}{c}\text { Trust-region- } \\
\text { dogleg }\end{array}$ & $\begin{array}{c}\text { Trust-region- } \\
\text { reflective }\end{array}$ & $\begin{array}{c}\text { Levenberg- } \\
\text { marquardt }\end{array}$ \\
\hline Mean \# steps & 15.56 & 17.55 & 17.52 \\
Std \# steps & 9.48 & 5.91 & 9.89 \\
Mean \# FEs & 41.16 & 55.65 & 80.84 \\
Std \# FEs & 26.38 & 17.85 & 34.57 \\
\hline
\end{tabular}

TABLE 3: Results obtained with Matlab fsolve for $R_{S}^{\text {guess }}=$ $0.9 R_{S, \text { ref }}^{\max }\left(n^{\text {guess }}\right)$.

\begin{tabular}{lccc}
\hline Algorithm & $\begin{array}{c}\text { Trust-region- } \\
\text { dogleg }\end{array}$ & $\begin{array}{c}\text { Trust-region- } \\
\text { reflective }\end{array}$ & $\begin{array}{c}\text { Levenberg- } \\
\text { marquardt }\end{array}$ \\
\hline Mean \# steps & 6.28 & 11.83 & 7.18 \\
Std \# steps & 2.28 & 4.35 & 2.42 \\
Mean \# FEs & 20.57 & 32.45 & 42.60 \\
Std \# FEs & 4.69 & 13.09 & 9.23 \\
\hline
\end{tabular}

TABLE 4: Results obtained with different Matlab functions with $R_{S}^{\text {guess }}=0.9 R_{S, \text { ref }}^{\max }\left(n^{\text {guess }}\right)$.

\begin{tabular}{|c|c|c|c|}
\hline $\begin{array}{l}\text { Matlab } \\
\text { function }\end{array}$ & fminsearch & lsqnonlin & lsqnonlin \\
\hline Algorithm & $\begin{array}{c}\text { Nelder-Mead } \\
\text { simplex method }\end{array}$ & $\begin{array}{l}\text { Trust-region- } \\
\text { reflective }\end{array}$ & $\begin{array}{l}\text { Levenberg } \\
\text { marquardt }\end{array}$ \\
\hline Mean \# steps & 127.2 & 9.80 & 7.14 \\
\hline Std \# steps & 20.09 & 3.74 & 1.69 \\
\hline Mean \# FEs & 254.8 & 32.35 & 44.70 \\
\hline Std \# FEs & 19.95 & 11.28 & 7.24 \\
\hline
\end{tabular}

The comparisons of the performance achievable by using various algorithms and initial guesses are reported in Tables 2,3 , and 4 : in particular the results are expressed in terms of average number (mean \# steps) and standard deviation (std \# steps) of iterations steps, average number (mean \# FEs) and standard deviation (std \# FEs) of function evaluations (FEs) (in Table 2 the initial guesses are the ones proposed in [22]).

It is worth noting that the proposed initial guess (26) allows obtaining effective results also by using one of the most generic solvers for minimization problems, fminsearch, which employs the Nelder-Mead simplex method discussed in Lagarias et al. [32]. By using instead more effective Matlab functions (such as fsolve or lsqnonlin) and algorithms (such 
as Levenberg-Marquardt [33] or trust-region-dogleg [34] algorithms) the number of iterations and FEs becomes extremely low (around 7 for the average number of iterations and 45 for the one of FEs). Consequently the computational costs of the proposed procedure is quite negligible, as the various soft computing based approaches, like the ones in [12-15], typically require thousands of FEs. In addition, it is worth noting that the obtained results have physical meaning for more than $97 \%$ of the total number of panels (11488 on 11764 PV panels). The unphysical solutions could be due to the impossibility of identifying the five-parameter model as was for the previous case of BP Q series PV panels. Nevertheless, since we do not have any information about how the datasheets are loaded into the CEC database, we assumed they were correct and no check was made about the exactness of data. Thus, some unphysical solutions could be also due to this last matter and caused by the presence of some errors within the CEC database. Finally, with the aim to show the importance of adopting an accurate 5-parameter model rather than approximated ones (such as for example the 3parameter and 4-parameter models [35]) the $I-V$ and $P-V$ curves at SRC for BP $3235 \mathrm{~T}$ module have been considered as last test. The 3-parameter and 4-parameter models seem to be very similar to the 5-parameter one. Nevertheless, with the aim to simplify the characterization problem, $R_{S, \text { ref }}=0$ and $R_{\mathrm{SH} \text {,ref }}=$ inf conditions are used for the 3-parameter model and $R_{\mathrm{SH}, \text { ref }}=\inf$ condition is used for the 4-parameter model. The $I-V$ and $P-V$ curves for the three models are shown in Figures 6 and 8, whereas the close-up around the maximum power point (MPP) is shown in Figures 7 and 9. It is evident, by observing the $P-V$ curves, that (1) the 5parameter and 4-parameter models are both accurate in the evaluation of MPP, whereas the 3-parameter model is not; (2) the 4-parameter model overestimates the power around the MPP, causing possible errors in the prediction of electric power produced by a PV plant.

\section{Conclusions}

In this paper a fast and accurate procedure has been presented for the characterization of thousands of photovoltaic modules in few seconds, by starting from the manufacturer datasheets. The proposed procedure utilizes the five-parameter model and takes advantage from its reduced form [22] in order to decrease the dimensions of the search space. Indeed, the reduced system provides a strong advantage in terms of convergence, computational costs, and execution time of the present approach (less than $30 \mathrm{msec}$ for each panel was spent on a simple Intel i5 core $2.5 \mathrm{GHz}$ based notebook). In particular, it allows (1) choosing suitable initial guesses within a well-defined feasible domain; (2) using very simple and standard numerical algorithms for finding parameters; (3) proving the existence, or not, of the unique physical solution of the five-parameter model for each PV panel; (4) proving the existence of only unphysical solutions for the cases in which the five-parameter model cannot be identified. The results of the tests performed on around 11.000 photovoltaic modules belonging to the CEC database demonstrated both the fastness and the effectiveness of the proposed method.

\section{Technical Parameters}

\begin{tabular}{|c|c|}
\hline$q:$ & $1.602 \times 10^{-19}(\mathrm{C})$ \\
\hline$k$ : & $1.3806503 \times 10^{-23}(\mathrm{~J} / \mathrm{K})$ \\
\hline$E_{g}:$ & Bandgap energy \\
\hline G: & Irradiance \\
\hline$T:$ & Cell temperature \\
\hline$I_{0}:$ & Reverse saturation current \\
\hline$I_{\text {irr }}:$ & Photocurrent \\
\hline$n:$ & Ideality factor \\
\hline$R_{S}:$ & Series resistance \\
\hline$R_{\mathrm{SH}}:$ & Shunt resistance \\
\hline$N_{s}:$ & Number of series modules/cells \\
\hline$N_{p}:$ & Number of parallel connected strings \\
\hline$T_{\text {ref }}:$ & $25^{\circ} \mathrm{C}$ at $\mathrm{SRC}$ \\
\hline$G_{\text {ref: }}:$ & $1000 \mathrm{~W} / \mathrm{m}^{2}$ at $\mathrm{SRC}$ \\
\hline$n_{\text {ref: }}:$ & Ideality factor at SRC \\
\hline$R_{S, \text { ref }}:$ & Series resistance at SRC \\
\hline$I_{\text {irr,ref }}:$ & Photocurrent at SRC \\
\hline$I_{0, \mathrm{ref}}:$ & Reverse saturation current at SRC \\
\hline$G_{\mathrm{SH}, \mathrm{ref}}=R_{\mathrm{SH}, \mathrm{ref}}^{-1}:$ & Shunt resistance at SRC \\
\hline$V_{\mathrm{OC}}:$ & Open circuit voltage \\
\hline$I_{\mathrm{SC}}:$ & Short circuit current \\
\hline$V_{\mathrm{mp}}:$ & Maximum power voltage \\
\hline$I_{\mathrm{mp}}:$ & Maximum power current \\
\hline$V_{\text {OC,ref }}:$ & Open circuit voltage at SRC \\
\hline$I_{\mathrm{SC}, \mathrm{ref}}:$ & Short circuit current at SRC \\
\hline$V_{\text {mp,ref: }}:$ & Maximum power voltage at SRC \\
\hline$I_{\text {mp,ref }}:$ & Maximum power current at SRC \\
\hline$\alpha_{T}:$ & Temperature coeff. for $I_{\mathrm{SC}}$ \\
\hline$\alpha_{T}^{\%}:$ & Percentage temperature coeff. for $I_{\mathrm{SC}}$ \\
\hline$\beta_{T}:$ & Temperature coeff. for $V_{\mathrm{OC}}$ \\
\hline$\beta_{T}^{\%}:$ & Percentage temperature coeff. for $V_{\mathrm{OC}}$ \\
\hline$C_{1}:$ & $k T_{\text {ref }} / q$ \\
\hline$C_{2}:$ & $V_{\mathrm{OC}, \mathrm{ref}} / N_{S} C_{1}$ \\
\hline$C_{3}:$ & $V_{\text {mp,ref }} / N_{S} C_{1}$ \\
\hline$C_{4}:$ & $I_{\mathrm{mp}, \mathrm{ref}} / N_{P} C_{1}$ \\
\hline$C_{5}:$ & $I_{\mathrm{SC}, \mathrm{ref}} / N_{P} C_{1}$ \\
\hline
\end{tabular}

\section{Conflict of Interests}

The authors declare that there is no conflict of interests regarding the publication of this paper.

\section{References}

[1] A. D. Rajapakse and D. Muthumuni, "Simulation tools for photovoltaic system grid integration studies," in Proceedings of the IEEE Electrical Power and Energy Conferenc (EPEC '09), pp. $1-5$, October 2009.

[2] D. Menicucci and J. Fernandez, User's Manual for PVFORM, SAND85-0376: A Photovoltaic System Simulation Program For Stand-Alone and Grid-Interactive Applications, Sandia National Laboratories, Albuquerque, NM, USA, 1988.

[3] “PVWATTS," 2011, http://www.nrel.gov/rredc/pvwatts/. 
[4] N. J. Blair, A. P. Dobos, and P. Gilman, "Comparison of photovoltaic models in the system advisor model," in Proceedings of the Solar, Baltimore, Md, USA, April 2013.

[5] J. Ma, K. Man, T. Ting, N. Zhang, S. U. Guan, and P. W. Wong, "Dem: direct estimation method for photovoltaic maximum power point tracking," Procedia Computer Science, vol. 17, pp. 537-544, 2013, 1st International Conference on Information Technology and Quantitative Management.

[6] I. T. Papaioannou and A. Purvins, "Mathematical and graphical approach for maximum power point modelling," Applied Energy, vol. 91, no. 1, pp. 59-66, 2012.

[7] M. Carrasco, F. Mancilla-David, F. R. Fulginei, A. Laudani, and A. Salvini, "A neural networks-based maximum power point tracker with improved dynamics for variable dc-link gridconnected photovoltaic power plants," International Journal of Applied Electromagnetics and Mechanics, vol. 43, no. 1, pp. 127135, 2013.

[8] B. Schulz, T. Glotzbach, C. Vodermayer, G. Wotruba, M. Mayer, and S. Grünsteidl, "Evaluation of calibrated solar cells and pyranometers regarding the effective irradiance detected by pv modules," in Proceedings of the 25th European Photovoltaic Solar Energy Conference and Exhibition/5th World Conference on Photovoltaic Energy Conversion, pp. 4797-4800, October 2012.

[9] F. Mancilla-David, F. Riganti-Fulginei, A. Laudani, and A. Salvini, "A neural network-based low-cost solar irradiance sensor," IEEE Transactions on Instrumentation and Measurement, vol. 63, no. 3, pp. 583-591, 2014.

[10] H. Tian, F. Mancilla-David, K. Ellis, E. Muljadi, and P. Jenkins, "A cell-to-module-to-array detailed model for photovoltaic panels," Solar Energy, vol. 86, no. 9, pp. 2695-2706, 2012.

[11] W. de Soto, S. A. Klein, and W. A. Beckman, "Improvement and validation of a model for photovoltaic array performance," Solar Energy, vol. 80, no. 1, pp. 78-88, 2006.

[12] L. L. Jiang, D. L. Maskell, and J. C. Patra, "Parameter estimation of solar cells and modules using an improved adaptive differential evolution algorithm," Applied Energy, vol. 112, pp. 185-193, 2013.

[13] K. Ishaque, Z. Salam, S. Mekhilef, and A. Shamsudin, "Parameter extraction of solar photovoltaic modules using penaltybased differential evolution," Applied Energy, vol. 99, pp. 297308, 2012.

[14] M. F. AlHajri, K. M. El-Naggar, M. R. AlRashidi, and A. K. Al-Othman, "Optimal extraction of solar cell parameters using pattern search," Renewable Energy, vol. 44, pp. 238-245, 2012.

[15] N. Rajasekar, N. K. Kumar, and R. Venugopalan, "Bacterial foraging algorithm based solar $\{\mathrm{PV}\}$ parameter estimation," Solar Energy, vol. 97, pp. 255-265, 2013.

[16] S. Xian Lun, C. Jiao Du, G. Hong Yang et al., "An explicit approximate iv characteristic model of a solar cell based on pad approximants," Solar Energy, vol. 92, pp. 147-159, 2013.

[17] S. Xian Lun, C. Jiao Du, T. Ting Guo, S. Wang, J. Shu Sang, and J. Pei Li, "A new explicit iv model of a solar cell based on taylors series expansion," Solar Energy, vol. 94, pp. 221-232, 2013.

[18] A. Jain and A. Kapoor, "Exact analytical solutions of the parameters of real solar cells using Lambert W-function," Solar Energy Materials and Solar Cells, vol. 81, no. 2, pp. 269-277, 2004.

[19] A. Jain and A. Kapoor, "A new method to determine the diode ideality factor of real solar cell using Lambert W-function," Solar Energy Materials and Solar Cells, vol. 85, no. 3, pp. 391396, 2005.
[20] Y. Chen, X. Wang, D. Li, R. Hong, and H. Shen, "Parameters extraction from commercial solar cells I-V characteristics and shunt analysis," Applied Energy, vol. 88, no. 6, pp. 2239-2244, 2011.

[21] R. M. Corless, G. H. Gonnet, D. E. G. Hare, D. J. Jeffrey, and D. E. Knuth, "On the Lambert W function," Advances in Computational Mathematics, vol. 5, no. 4, pp. 329-359, 1996.

[22] A. Laudani, F. Mancilla-David, F. Riganti-Fulginei, and A. Salvini, "Reduced-form of the photovoltaic five-parameter model for efficient computation of parameters," Solar Energy, vol. 97, pp. 122-127, 2013.

[23] California Energy Commission, "CECPV calculator version 4.0," 2013, http://www.gosolarcalifornia.org/tools/nshpcalculator/index.php.

[24] V. lo Brano, A. Orioli, G. Ciulla, and A. di Gangi, "An improved five-parameter model for photovoltaic modules," Solar Energy Materials and Solar Cells, vol. 94, no. 8, pp. 1358-1370, 2010.

[25] A. Mermoud and T. Lejeune, "Performance assessment of a simulation model for PV modules of any available technology," in Proceedings of the 25th European PV Solar Energy Conference, pp. 4786-4791, 2010.

[26] A. P. Dobos, "An improved coefficient calculator for the california energy commission 6 parameter photovoltaic module model," Journal of Solar Energy Engineering, Transactions of the ASME, vol. 134, no. 2, Article ID 021011, pp. 1-6, 2012.

[27] Y. Li, W. Huang, H. Huang et al., "Evaluation of methods to extract parameters from currentvoltage characteristics of solar cells," Solar Energy, vol. 90, pp. 51-57, 2013.

[28] J. Fourie, R. Green, and Z. W. Geem, "Generalised adaptive harmony search: a comparative analysis of modern harmony search," Journal of Applied Mathematics, vol. 2013, Article ID 380985, 13 pages, 2013.

[29] A. Laudani, F. Riganti-Fulginei, and A. Salvini, "Closed forms for the fully-connected continuous flock-of-starlings optimization algorithm," in Proceedings of the 15th International Conference on Computer Modeling and Simulation (UKSim '13), April 2013.

[30] A. Laudani, F. Riganti-Fulginei, A. Salvini, M. Schmid, and S. Conforto, "CFSO": a new supervised swarm-based optimization algorithm," Mathematical Problems in Engineering, vol. 2013, Article ID 560614, 13 pages, 2013.

[31] F. R. Fulginei, A. Salvini, and G. Pulcini, "Metric-topologicalevolutionary optimization," Inverse Problems in Science and Engineering, vol. 20, no. 1, pp. 41-58, 2012.

[32] J. C. Lagarias, J. A. Reeds, M. H. Wright, and P. E. Wright, "Convergence properties of the Nelder-Mead simplex method in low dimensions," SIAM Journal on Optimization, vol. 9, no. 1, pp. 112-147, 1998.

[33] J. J. Moré, “The levenberg-marquardt algorithm: implementation and theory," in Numerical Analysis, pp. 105-116, Springer, New York, NY, USA, 1978.

[34] T. F. Coleman and Y. Li, "An interior trust region approach for nonlinear minimization subject to bounds," SIAM Journal on Optimization, vol. 6, no. 2, pp. 418-445, 1996.

[35] A. Luque and S. Hegedus, Handbook of Photovoltaic Science and Engineering, John Wiley \& Sons, New York, NY, USA, 2011. 

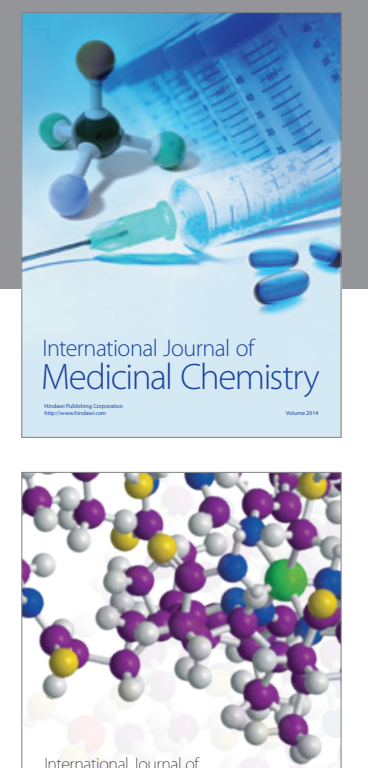

\section{Carbohydrate} Chemistry

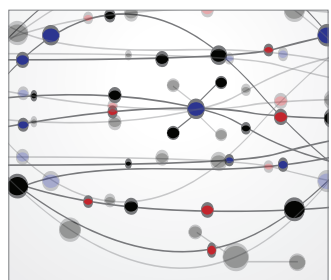

The Scientific World Journal
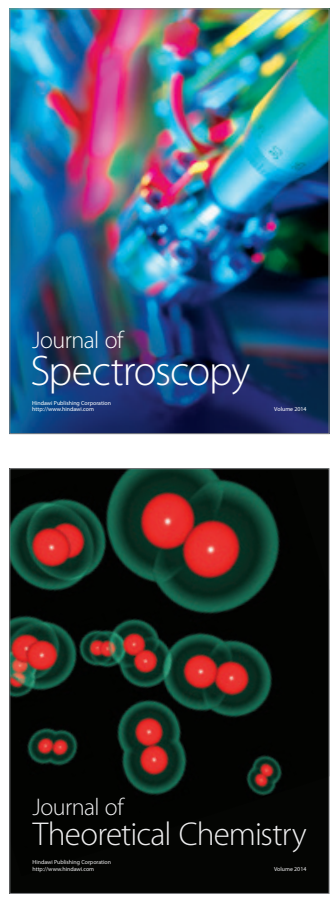
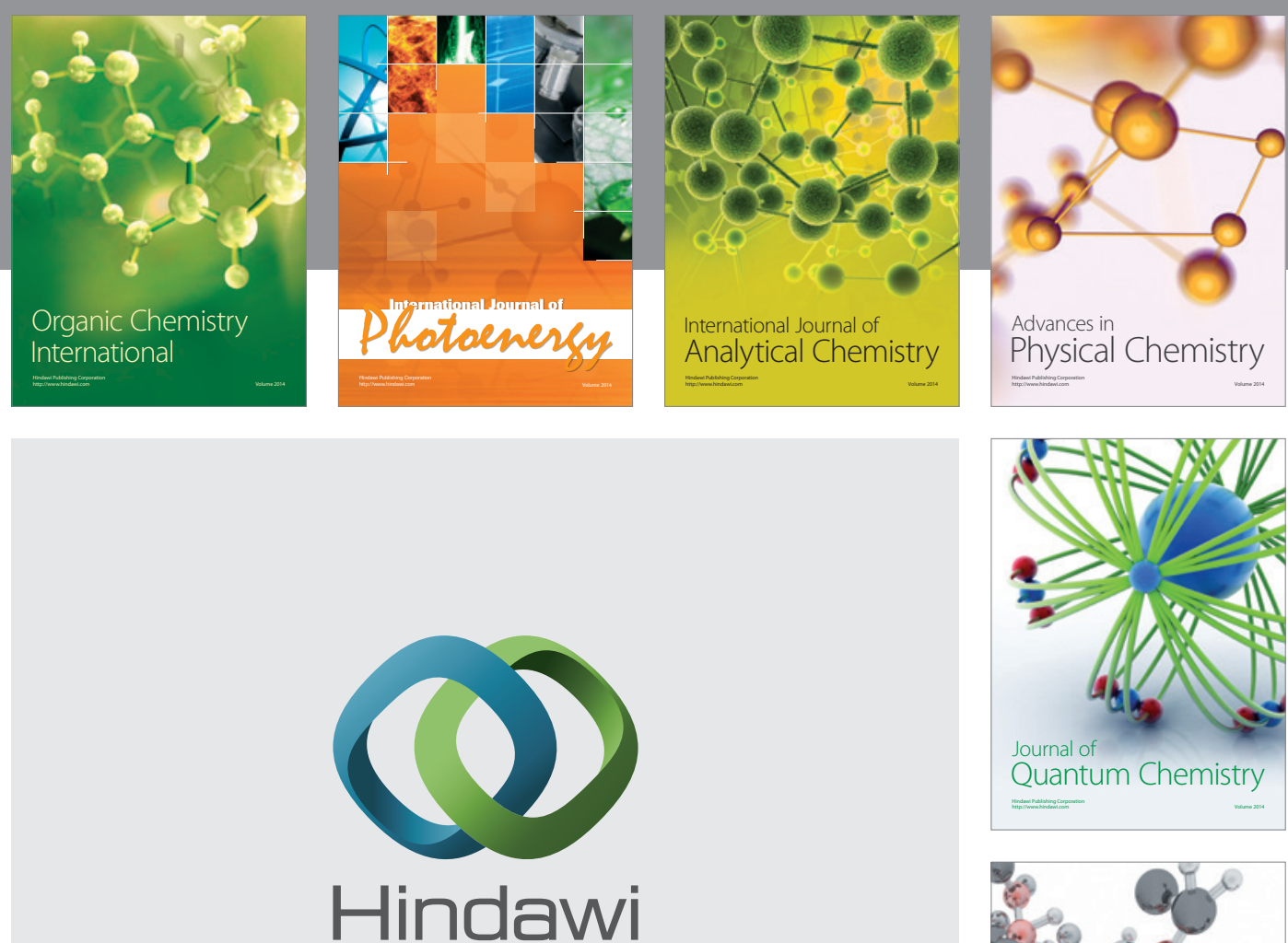

Submit your manuscripts at

http://www.hindawi.com

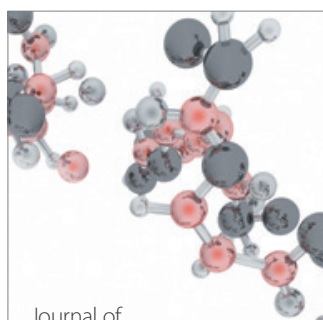

Analytical Methods

in Chemistry

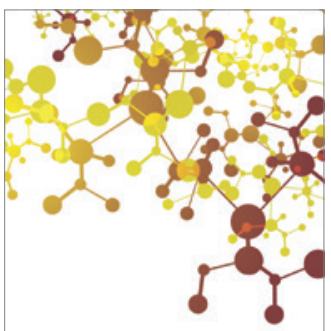

Journal of

Applied Chemistry

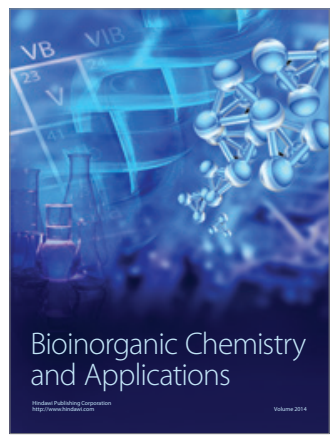

Inorganic Chemistry
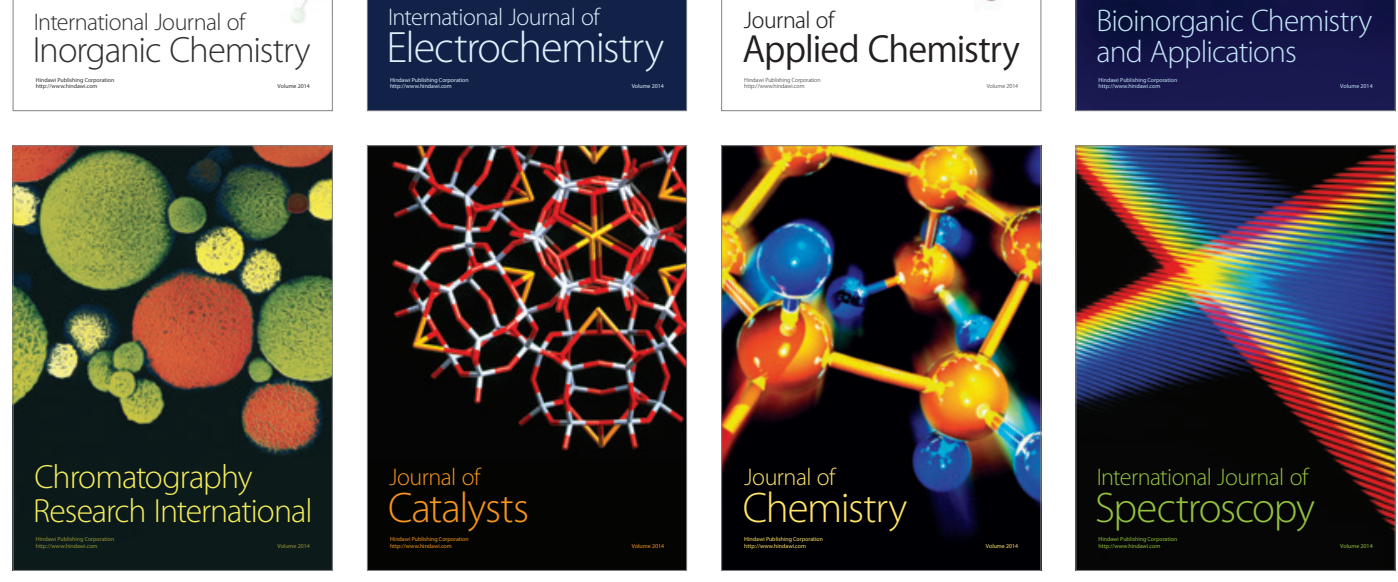